\title{
Real-life isoniazid and rifampicin plasma concentrations in children: a tool for therapeutic drug monitoring of tuberculosis
}

\author{
Chiara Tersigni ${ }^{1}$, Giulia Boiardi ${ }^{2}$, Lorenzo Tofani ${ }^{3}$, Elisabetta Venturini ${ }^{4}$, Carlotta Montagnani ${ }^{4}$, Barbara Bortone ${ }^{4}$,
} Leila Bianchi ${ }^{4}$, Elena Chiappini ${ }^{4}, 5$, Maria Iris Cassetta ${ }^{3}$, Stefania Fallani ${ }^{3}$, Andrea Novelli ${ }^{3}$ and Luisa Galli4 ${ }^{4 *}$

\begin{abstract}
Background: Low plasma levels of first-line antitubercular drugs can be counted among the main causes of poor response to antitubercular therapy, and therapeutic drug monitoring has been proposed as a method to promote tailored treatments for both child and adult patients. The main aim of the study was to evaluate serum concentrations of isoniazid (INH) and rifampicin (RIF) and to investigate reasons for sub-therapeutic plasma concentrations in order to fix dosages.

Methods: Children with TB were prospectively enrolled from January to August 2019. Two venous blood samples were collected (the first at least 15 days after the beginning of antitubercular treatment, and the second between 1 and 8 weeks later). Plasma concentrations were determined by a validated high-performance liquid chromatography method.

Results: In all, 45 children were included. Seventy blood samples for INH plasma concentration were collected between 120 and $240 \mathrm{~min}$ after drug intake. Adjusting for dose (mg/kg/day) and time of INH administration, when considering three different age groups ( $\leq 2$ years, 2-12 years, $>12$ years), a statistically significant lower INH plasma concentration was observed in younger children compared to the older age groups in the multivariate analysis $(p<0.001$ and $p<0.001)$. A total of 68 blood samples were evaluated for RIF concentrations. Both for INH and RIF a statistically significant lower plasma concentration was also observed in adolescents $(p<0.001)$. Fifteen children $(15 / 45$, 33\%) presented drug concentrations under the referral therapeutic range.
\end{abstract}

Conclusions: Based on our findings, monitoring patients'drug plasma concentrations in children under 2 years of age and in adolescents can make treatment more patient-tailored.

Keywords: Therapeutic drug monitoring, Children, Tuberculosis, Treatment compliance, Isoniazid, Rifampicin

\section{Background}

Tuberculosis (TB) is one of the leading causes of human morbidity and mortality from a curable infectious disease and remains a major global health problem [1]. Despite

*Correspondence: luisa.galli@unifi.it

${ }^{5}$ Department of Health Sciences, University of Florence, Anna Meyer

Children's University Hospital, Florence, Italy

Full list of author information is available at the end of the article the fact that the incidence rate has been decreasing since 2000, TB still ranks among the top ten causes of death [1, 2]. Furthermore, childhood TB can be considered a sentinel of the disease spreading in the community, mostly because children are at a significantly higher risk than adults of developing the active form of the disease $[2,3]$. As a result, pediatric TB deserves prompt identification and treatment [4]. 
Several studies have investigated the different causes of antitubercular treatment failures. The lack of adherence to therapeutic regimens, drug resistant strains, the presence of comorbidities and the variability in the pharmacokinetics of first-line TB drugs were identified as the most important factors [5, 6]. Furthermore, it is estimated that nearly $15 \%$ of patients treated for active and latent $\mathrm{TB}$ present a poor response to treatment regimens [5]. A large inter-patient variability of plasma levels of isoniazid (INH), with plasma concentrations frequently below the expected therapeutic range has been observed in most studies [5-7]. Low plasma levels of first-line antitubercular drugs can be counted as being among the main causes of poor response to therapy. Furthermore, a delayed or insufficient treatment response can lead to prolonged therapy, and consequently to the development of resistant strains or possible relapses of the disease $[8$, 9].

However, early biomarkers which can identify patients requiring prolonged treatments or predict treatment efficacy have yet to be found [8]. For this reason, therapeutic drug monitoring (TDM) has been proposed as a method for evaluating patient compliance with therapy, in order to fix drug doses on the basis of plasma concentrations. These strategies can make therapies more patient-tailored and can avoid the development of resistant strains, which might result from drug concentrations far below therapeutic values, or they can prevent the occurrence of adverse reactions related to supra-therapeutic levels [10, 11 .

In the literature, there is a lack of published studies regarding plasma concentration of INH and rifampicin (RIF) in children, especially under 2 years of age, with referral therapeutic ranges often based on adult studies $[12,13]$. However, these studies are fundamental to guiding recommended pediatric TB drug dosages. In fact, in 2010 the WHO revised its guidelines to suggest higher doses of first line antitubercular drugs (INH 10-15 mg/ $\mathrm{kg} /$ day versus $4-6 \mathrm{mg} / \mathrm{kg} /$ day and RIF $10-20 \mathrm{mg} / \mathrm{kg} /$ day versus $8-12 \mathrm{mg} / \mathrm{kg} /$ day), based on studies conducted on older children or adults [14-17].

The present study aims to evaluate serum concentrations of INH and RIF in children treated for latent and active TB. It will investigate reasons for sub-therapeutic plasma concentrations of INH and RIF in order to fix dosages when necessary, promote a patient-tailored treatment and prevent treatment failure and the onset of drug resistant strains.

\section{Methods}

Children ( $0-18$ years) with active and latent TB treated with INH and RIF were prospectively enrolled at the Pediatric Infectious Diseases Unit of a tertiary care pediatric university hospital located in Florence, Italy (Anna Meyer Children's University Hospital) from January 2019 to August 2019. An average of 45 latent and 25 active cases a year are evaluated in the TB clinic. The following data were collected in the present prospective observational study: demographic characteristics and treatment information (drug type, dosage, therapy start and end dates, time of drug intake, adverse events and associated drugs). All data were recorded in the study database following the international standards for the protection of privacy and personal information. The study was approved by the ethical committee (20/12/2018-188/2018).

\section{Study design}

Children were included in the present study within their first clinical examination, at least 15 days after the beginning of antitubercular therapy (achieved steady state of INH and RIF) [15]. During the first evaluation, a clinical assessment was made of the reason for investigations and the presence or absence of TB drug-related side effects. Microbiological data (in cases of active TB) were collected. Routine blood exams were carried out to detect any adverse reactions (full cell blood count, creatinine, c-reactive protein and serum transaminases). A venous blood sample (4 $\mathrm{ml}$ in EDTA) was added to the routine blood tests at least 1 week after the beginning of antitubercular treatment (median 54 days, IQR: 30.7-94.7).

The same sample was taken in one of the following scheduled evaluations, between 1 and 8 weeks after the first. Blood samples were centrifuged immediately after collection and the plasma was separated and stored at $-20{ }^{\circ} \mathrm{C}$ until analysis. Concentrations were determined by a validated High Performance Liquid Chromatography (HLPC) method [18, 19].

INH samples and calibration standards were extracted with Amicon Ultra $0.5 \mathrm{ml} 10 \mathrm{~K}$ filters and $180 \mu \mathrm{l}$ of the filtrate was injected into the column. A symmetry C18 column $(250 \times 4.6 \mathrm{~mm}, 5 \mu \mathrm{m}$; Waters, Milford, MA, USA) was used for the INH analysis. INH was isocratically eluted at $263 \mathrm{~nm}$ at a constant flow rate of $1.0 \mathrm{ml} /$ min. The mobile phase was made up of ammonium acetate $50 \mathrm{mM}$ and methanol, 90:10 (v/v). The column was kept at room temperature for the entire duration of the analysis. Calibration curves were performed in a pool of plasma with the addition of INH at the following concentrations $8,4,2,1,0.5,0.25 \mathrm{mg} / 1$ [18].

RIF samples and calibration standards were extracted with acetonitrile $(33: 67 \mathrm{v} / \mathrm{v})$ in polypropylene tubes (Sarstedt, Leicester, UK). The mixture was briefly vortexmixed, kept for $10 \mathrm{~min}$ at room temperature and then centrifuged at $1200 \times g$ for $10 \mathrm{~min}$. The supernatant was dried, the dry residue reconstituted with $0.5 \mathrm{ml}$ of mobile phase, and $180 \mu \mathrm{l}$ was injected into the column. A Luna 
C18 column $(250 \times 4.6 \mathrm{~mm}$ ID, $5 \mu \mathrm{m}$; Phenomenex, Torrance, CA, USA) protected by an adequate pre-column was used for RIF analysis. RIF was isocratically eluted at $254 \mathrm{~nm}$ at a constant flow rate of $1.2 \mathrm{ml} / \mathrm{min}$. The mobile phase consisted of potassium dihydrogen phosphate $0.05 \mathrm{M}(\mathrm{pH} 2.6)$ and acetonitrile 55:45 (v/v). The column was kept at room temperature for the entire duration of the analysis. Calibration curves were carried out in a plasma pool with the addition of RIF at the following concentrations 16, 8, 4, 2, 1, 0.5, $0.25 \mathrm{mg} / \mathrm{l}$ [19].

Both INH and RIF assays were linear $(r=0.9997)$ in the $0.1-25 \mathrm{mg} / \mathrm{l}$ concentration range. Precision and accuracy coefficients of variation were between 2.4 and $7.3 \%$; intraday accuracy was in the range of $95-106.5 \%$.

On the basis of INH and RIF pharmacokinetic parameters, samples were collected between a minimum of 2 and a maximum of $8 \mathrm{~h}$ after drug administration. Blood samples evaluated for the statistical analysis were obtained between 120 and 240 min after drug intake [20]. Patients with unknown sampling times and those receiving the study drugs more than $8 \mathrm{~h}$ before sampling were excluded from the analysis.

\section{Definitions}

Active TB cases were diagnosed according to two categories:

(1) Definite TB: children with Mycobacterium tuberculosis cultured or detected by microscopy or molecular methods from gastric aspirate culture or sputum;

(2) Probable TB: absence of microbiological confirmation but presence of the following criteria: abnormal radiography and/or computed tomography scan consistent with lung TB, positive clinical response to TB therapy, clinical signs and symptoms of active $\mathrm{TB}$, and either a history of TB contact or travel to a TB-endemic country within the last 24 months [21].

Latent TB was diagnosed in children with a positive tuberculin skin test and/or interferon- $\gamma$ release test, without clinical or radiological signs of active disease [19].

According to available studies conducted in children, the INH considered reference range was $3-5 \mu \mathrm{g} / \mathrm{ml}$ after $2 \mathrm{~h}$ and $1-3 \mu \mathrm{g} / \mathrm{ml}$ after $4 \mathrm{~h}$. The RIF considered therapeutic range was $8-24 \mu \mathrm{g} / \mathrm{ml}$ after $2 \mathrm{~h}$ based on two studies conducted in adults. [22-25].

\section{Statistical analysis}

Statistical analysis was performed using SAS 9.3. In order to evaluate the normal distribution of continuous variables, the Shapiro-Wilk test was used. For each continuous variable, the mean and standard deviation (SD) or median and interquartile range (IQR) (according to the Shapiro-Wilk test result) is reported. For categorical variables, absolute frequencies and percentages are reported for each category. To evaluate the association between a single RIF or INH dosage and each covariate, a simple linear regression was used. In order to assess associations between all RIF or INH dosages and patient characteristics (age, sex and ethnicity) a simple and multiple GEE (generalized estimating equation model) linear model was used, including all characteristics (such as age, sex and ethnicity). The significant level was set at $5 \%$.

\section{Results}

Children diagnosed with active or latent $\mathrm{TB}$ were enrolled in the present study. Overall, 45 children were included ( 19 with active TB and 26 with latent TB) with a median age of 82 months [IQR 38-148]. The anagraphic data and the main characteristics of enrolled children are reported in Table 1.

\section{Treatment regimen and side effects in children with active and latent TB}

Children with active TB were 19/45 (42.2\%), of which $17 / 19$ (89.5\%) were treated with a four-drug regimen comprised of INH, RIF, pyrazinamide (PZN) and

Table 1 General characteristics of enrolled children

\begin{tabular}{|c|c|c|c|}
\hline Patients characteristics & $\begin{array}{l}\text { Latent TB } \\
\mathrm{n}=\mathbf{2 6}\end{array}$ & $\begin{array}{l}\text { Active TB } \\
\mathrm{n}=19\end{array}$ & $\begin{array}{l}\text { All } \\
n=45\end{array}$ \\
\hline \multicolumn{4}{|l|}{ Sex } \\
\hline Male & 17/26 (65.4\%) & 15/19 (78.9\%) & $32 / 45(71.1 \%)$ \\
\hline Female & 9/26 (34.6\%) & 4/19 (21.1\%) & 13/45 (28.9\%) \\
\hline $\begin{array}{l}\text { Age (months) — median } \\
\text { [IQRs] }\end{array}$ & $101[64-187]$ & $43[22-134]$ & 82 [38-148] \\
\hline \multicolumn{4}{|l|}{ Reason for investigation } \\
\hline $\begin{array}{l}\text { Adoption/immigrant } \\
\text { screening }\end{array}$ & $11 / 26(42.3 \%)$ & $0 / 19$ & $11 / 45(24.4 \%)$ \\
\hline Household contact & $12 / 26(46.2 \%)$ & 6/19 (31.6\%) & $18 / 45(40 \%)$ \\
\hline Symptomatic & $0 / 26$ & 11/19 (57.9\%) & $11 / 45$ (24.4\%) \\
\hline Not household contact & $3 / 26(11.5 \%)$ & $2 / 19(10.5 \%)$ & $5 / 45(11.2 \%)$ \\
\hline \multicolumn{4}{|l|}{ Ethnicity } \\
\hline Caucasian & 15/26 (57.7\%) & 10/19 (52.6\%) & $25 / 45(55.5 \%)$ \\
\hline African & $0 / 26$ & $4 / 19(21 \%)$ & $4 / 45(8.9 \%)$ \\
\hline Asian & $3 / 26(11.5 \%)$ & $2 / 19(10.5 \%)$ & $5 / 45(11.1 \%)$ \\
\hline South American & $8 / 26(30.8 \%)$ & $3 / 19(15.8 \%)$ & $11 / 45(24.5 \%)$ \\
\hline \multicolumn{4}{|l|}{ Type of TB } \\
\hline $\begin{array}{l}\text { Microbiological con- } \\
\text { firmed }\end{array}$ & - & 9/19 (47.3\%) & - \\
\hline $\begin{array}{l}\text { No microbiological } \\
\text { confirmed }\end{array}$ & - & 11/19 (57.9\%) & - \\
\hline
\end{tabular}

$T B$ tuberculosis; IQR interquartile range 
ethambutol (ETB), and 2/19 (10.5\%) with RIF, PZN and ETB (due to the onset of INH resistance). Eleven out of 19 children (57.9\%) were evaluated because the presence of TB symptoms (prolonged fever, persistent cough), and 9/19 because of contact with active TB cases. Four children (21\%) presented vomiting and abdominal pain as side effects of treatment, with transaminase values within the physiological range in the totality of patients. No side effects caused treatment discontinuation. The majority of patients had pulmonary TB (63.1\%) with Mycobacterium tuberculosis cultured or detected by microscopy or molecular methods from gastric aspirate in about half of the cases $(9 / 19,47.3 \%)$.

Patients diagnosed with latent TB were 26/45 (57.8\%). Twenty-one $(80.8 \%)$ were treated with a two-drug regimen comprised of INH and RIF, and 4/26 (15.4\%) with INH alone. The remaining patient was treated with RIF due to the onset of INH resistance.

The majority of these patients presented no adverse events to the antitubercular therapy. Only two patients
(7.7\%) reported vomiting. The routine blood exams showed transaminase values within the physiological range in $24 / 26$ (92.3\%) patients and slightly elevated in one patient. Only one case of hypertransaminasemia was reported, which led to the treatment being suspended for a month (plasma concentrations of INH and RIF were both in the referral therapeutic range).

\section{Isoniazid plasma concentrations}

Overall, 43 blood samples were collected during the first evaluation and 37 during the second scheduled clinical assessment. The median regimen duration of children treated with INH was 54 (IQR 33-95) days and 85 (IQR 19-64) days during the first and the second evaluations respectively.

Overall, 73 blood samples were collected between 120 and $240 \mathrm{~min}$ after drug intake. Time of INH samples collection is reported in Fig. 1.

No statistically significant variations of INH concentration in the first and second blood samples were detected,
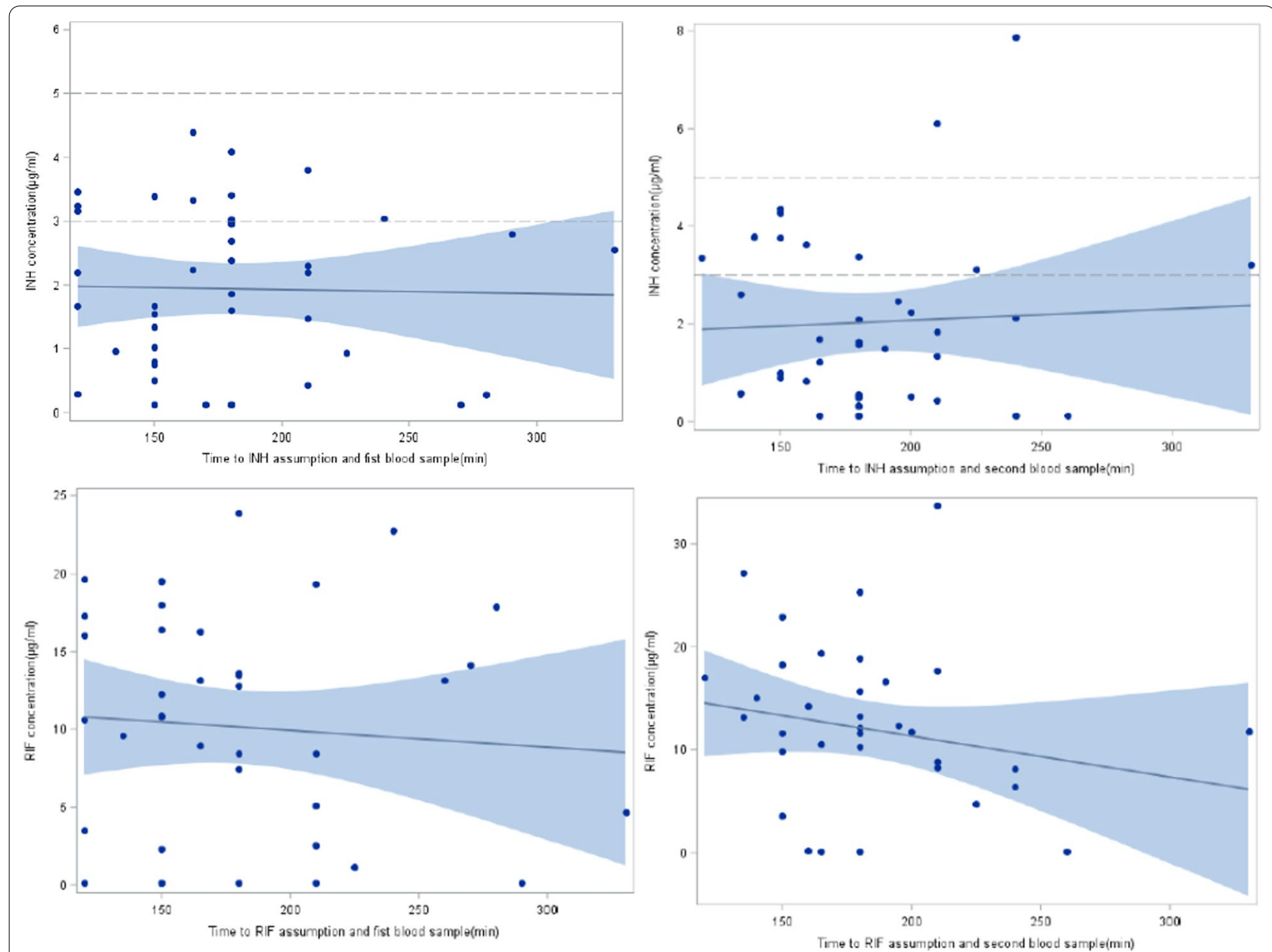

Fig. 1 Isoniazid and rifampicin times of samples collection 
when age at the beginning of INH treatment, gender and duration of therapy $(\mathrm{p}=0.57, \mathrm{p}=0.62$ and $\mathrm{p}=0.83)$ (Fig. 2, 3) were taken into account.

Mean INH plasma concentrations 2-4 h after drug intake were $1.95 \mu \mathrm{g} / \mathrm{ml}(\mathrm{SD} \pm 1.25)$ in the first blood sample and $2.04 \mu \mathrm{g} / \mathrm{ml}(\mathrm{SD} \pm 1.79)$ in the second, with an overall mean of $1.99 \mu \mathrm{g} / \mathrm{ml}(\mathrm{SD} \pm 1.51)$.

Since duration of INH administration showed no statistically significant correlation with INH plasma concentration both in the first and in the second evaluations ( $p=0.77$ and $p=27$, respectively), patient blood samples were analyzed overall.

With regard to reasons for investigation (symptomatic vs contact of TB index case) and type of TB (microbiological-confirmed vs. non-microbiological-confirmed), no statistically significant differences of INH concentrations were observed in the two groups $(\mathrm{p}=0.95$ and $\mathrm{p}=0.89$, respectively).

When adjusting for the dose $(\mathrm{mg} / \mathrm{kg} / \mathrm{day})$ of administered INH, drug concentrations showed a statistically significant difference by sex, being higher in male than female (median $2.22 \mu \mathrm{g} / \mathrm{ml}$ IQR $1.13-3.29$ vs $0.75 \mu \mathrm{g} / \mathrm{ml}$ IQR 0.44-1.67; $\mathrm{p}=0.0115)$ patients. However, when considering different age groups ( $\leq 12$ years vs $>12$ years), only INH concentrations in older males statistically differed from those found in females $(p=0.04)$.

In respect of patients' place of birth, no statistically significant differences were observed $(p=0.09)$.

Adjusting for the dose $(\mathrm{mg} / \mathrm{kg} / \mathrm{day})$ and for the time of INH administration, when considering three different age groups ( $\leq 2$ years, $2-12$ years, $>12$ years), a statistically significant lower INH plasma concentration was observed in younger children compared to the older age groups $(p=0.001$ and $p=0.0024)$. This finding was also

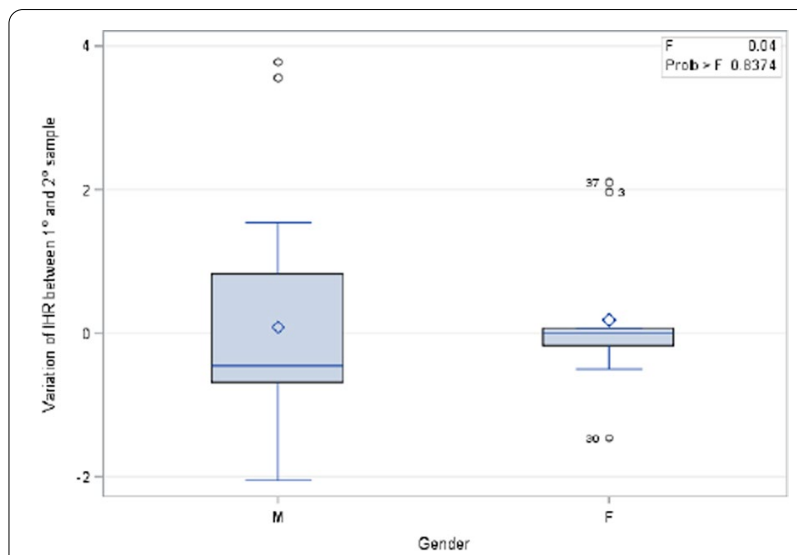

Fig. 3 Analysis of simple regression (blue line) and its $95 \% \mathrm{Cl}$ (blue band) for variation of isoniazid level and age at the beginning of therapy (figure on the left) and duration of therapy (figure in the right) between the first and the second blood sample

confirmed in the multivariate analysis $(\mathrm{p}<0.001$ and $\mathrm{p}<0.001$ ) (Table 2).

A statistically significant lower INH plasma concentration was also observed in children aged $>12$ years $(\mathrm{p}<0.001)$.

\section{Rifampicin plasma concentrations}

Thirty-nine blood samples were collected during the first evaluation and 37 during the second scheduled clinical assessment. Overall, 68 blood samples were evaluated for RIF plasma concentration. No statistically significant differences by sex or patient place of birth were observed $(\mathrm{p}=0.24$ and $\mathrm{p}=0.92$, respectively).

Mean RIF plasma concentrations $2-4 \mathrm{~h}$ after drug intake were $10.13 \mu \mathrm{g} / \mathrm{ml}(\mathrm{SD} \pm 7.22)$ in the first blood
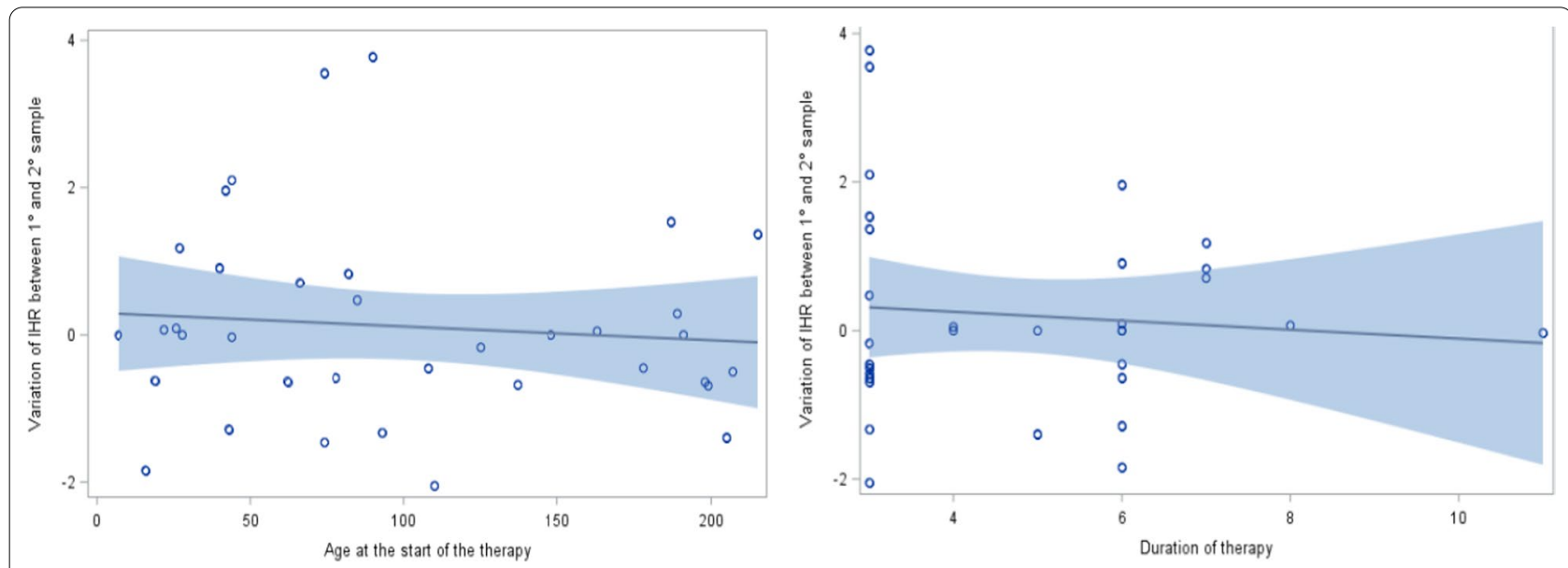

Fig. 2 Variation of isoniazid level and gender between the first and the second blood sample 
Table 2 Univariate and multivariate analysis of isoniazid concentration considering age, gender and ethnicity

\begin{tabular}{|c|c|c|c|c|}
\hline & n (\%) & $\begin{array}{l}\text { Median plasma concentration } \mu \mathrm{g} / \\
\mathrm{ml}(\mathrm{IQR})\end{array}$ & $\begin{array}{l}\text { Univariate analysis } \\
\mathrm{p}\end{array}$ & $\begin{array}{l}\text { Multivariate } \\
\text { analysis } \\
\text { p }\end{array}$ \\
\hline \multicolumn{5}{|l|}{ Age groups (years) } \\
\hline$\leq 2$ years & $10(13.7)$ & $0.78(0.43-1.86)$ & & \\
\hline $2-12$ years & $42(57.5)$ & $2.27(1.34-3.39)$ & 0.0024 & $<0.001$ \\
\hline$>12$ years & $21(28.8)$ & $1.55(0.5-2.47)$ & $<0.001$ & $<0.001$ \\
\hline \multicolumn{5}{|l|}{ Gender } \\
\hline Male & $52(71.2)$ & $2.22(1.13-3.29)$ & 0.01 & 0.056 \\
\hline Female & $21(28.8)$ & $0.75(0.44-1.67)$ & & \\
\hline \multicolumn{5}{|l|}{ Ethnicity } \\
\hline African & $5(6.8)$ & $2.61(2.20-3.24)$ & 0.90 & 0.238 \\
\hline Asiatic & $7(9.6)$ & $0.94(0.44-4.35)$ & 0.52 & 0.88 \\
\hline South American & $14(19.2)$ & $2.05(0.52-2.96)$ & 0.74 & 0.86 \\
\hline Caucasian & $47(64.4)$ & $1.67(0.80-3.12)$ & & \\
\hline
\end{tabular}

Value reported in bold those statistically significant $(p<0.05)$

$I Q R$ interquartile range

sample and $11.67 \mu \mathrm{g} / \mathrm{ml}(\mathrm{SD} \pm 8.23)$ in the second, with an overall mean of $10.88 \mu \mathrm{g} / \mathrm{ml}(\mathrm{SD} \pm 7.72)$.

In addition, no statistically significant variations of RIF concentration in the first and in the second blood sample were detected when considering age at the beginning of RIF treatment, sex and duration of therapy $(p=0.64$, $\mathrm{p}=0.24$ and $\mathrm{p}=0.39$, respectively) (Figs. 4 and 5).

Time of RIF samples collection is reported in Fig. 1.

Because duration of RIF administration showed no statistically significant correlation with RIF plasma concentration, both in the first and in the second evaluation $(\mathrm{p}=0.94$ and $\mathrm{p}=0.26$, respectively), blood samples of patients were analyzed overall.

Concerning reasons for investigation (symptomatic vs contact of TB index case) and type of TB (microbiological-confirmed vs. non-microbiological-confirmed), no statistically significant differences of RIF concentrations were observed in the two groups $(p=0.3$ and $p=0.051$, respectively).

Adjusting for the dose ( $\mathrm{mg} / \mathrm{kg} /$ day) of administered RIF, no statistically significant differences were observed between the sexes, both in the univariate and multivariate analyses $(\mathrm{p}=0.24)$ (Table 3$)$.

Regarding patients' place of birth, a statistically significant higher plasma concentration was observed in Africans compared to other ethnicities in the multivariate analysis $(\mathrm{p}<0.001)$.

Adjusting for the dose $(\mathrm{mg} / \mathrm{kg} /$ day) and for the time at RIF administration, when considering three different age groups ( $\leq 2$ years, $2-12$ years, $>12$ years), a statistically significant higher RIF plasma concentration was observed in children aged $2-12$ years $(\mathrm{p}<0.001)$.

\section{Children with subtherapeutic concentrations of INH and RIF}

Fifteen children $(15 / 45,33 \%)$ presented drug concentrations under the referral therapeutic range either for INH or RIF.

With particular regard to INH, seven children had subtherapeutic values of INH both in the first and in the second blood samples. For RIF, 4 children had subtherapeutic values of the drug, both in the first and in the second blood samples.

Three children had permanent (both in the first and in the second blood samples, and for both drugs) subtherapeutic concentrations of INH and RIF.

One child was an 11-year-old Italian boy, treated for active TB with a four-drug regimen, with a median dose of INH of $8.82 \mathrm{mg} / \mathrm{kg} /$ day and of RIF $17.64 \mathrm{mg} /$ $\mathrm{kg} /$ day.

The other two children were two brothers from Romania treated for latent TB. Over the course of their scheduled evaluations, reduced compliance by the family was observed.

\section{Discussion}

To our knowledge, this is one of the few pediatric studies which aims to apply a TDM approach to antitubercular treatment through the evaluation of INH and RIF plasma concentrations using an HPLC method. Although TDM is recognized to be an important tool for TB treatment, it has not yet been applied in the clinical routine, and is reserved for patients with a more serious illness or nonresponders [24]. 

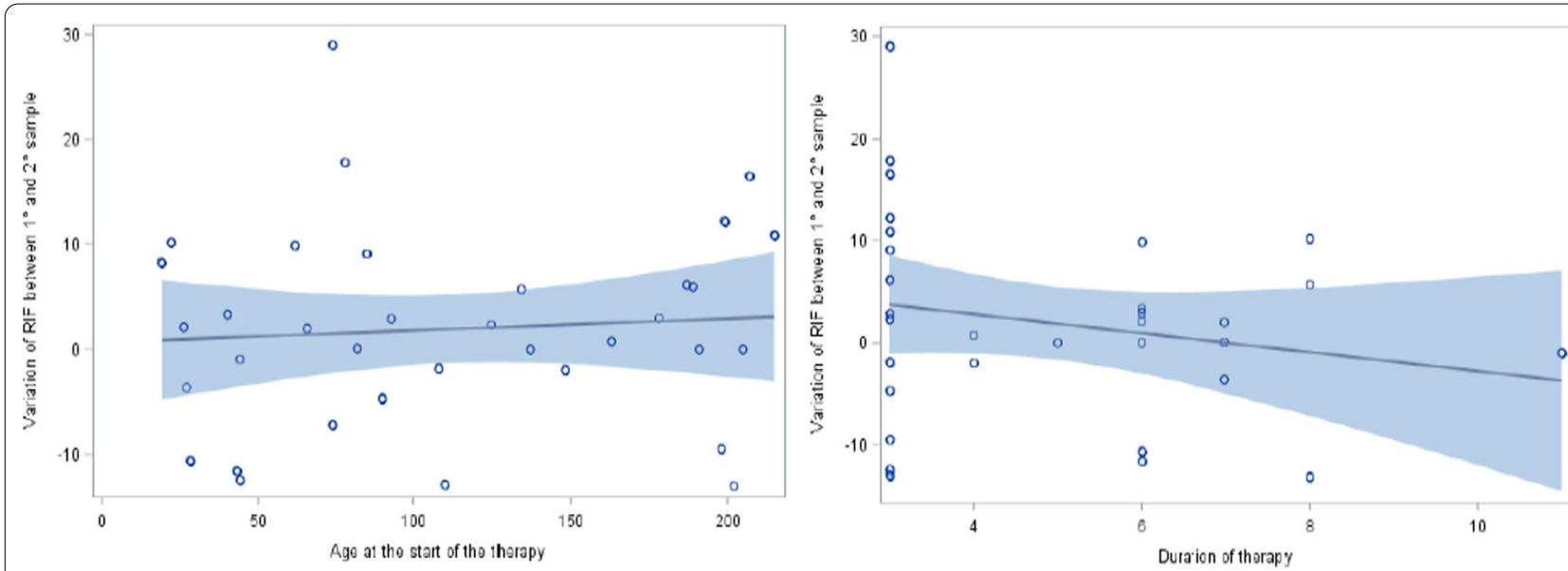

Fig. 4 Variation of rifampicin level and gender between the first and the second blood sample

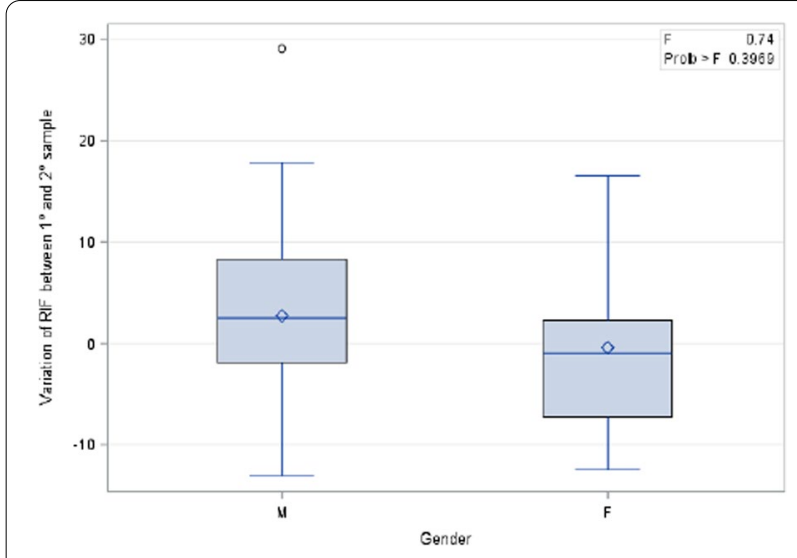

Fig. 5 Analysis of simple regression (blue line) and its 95\% Cl (blue band) for variation of rifampicin level and age at the beginning of therapy (figure on the left) and duration of therapy (figure on the right) between the first and the second blood sample

Overall, 45 children diagnosed with latent or active TB were prospectively enrolled in the present study. Mean plasma concentration 2-4 h after drug intake was $1.99 \mu \mathrm{g} / \mathrm{ml}(\mathrm{SD} \pm 1.51)$ for INH and $10.88 \mu \mathrm{g} / \mathrm{ml}$ $(\mathrm{SD} \pm 7.72)$ for RIF. Fifteen children (33\%) presented drug concentrations under the referral therapeutic range either for INH or RIF. Both for INH and RIF, no correlation with duration of therapy was observed $(\mathrm{p}=0.89$ and $\mathrm{p}=0.39$ respectively).

Differently from our results, in a study conducted by Fahimi et al., a statistically significant correlation between INH therapy duration and plasma concentrations was
Table 3 Univariate and multivariate analysis of rifampicin concentration considering age, gender and ethnicity

\begin{tabular}{|c|c|c|c|c|}
\hline & n (\%) & $\begin{array}{l}\text { Median plasma } \\
\text { concentration } \\
\mu \mathrm{g} / \mathrm{ml} \text { (IQR) }\end{array}$ & $\begin{array}{l}\text { Univariate } \\
\text { analysis } \\
p\end{array}$ & $\begin{array}{l}\text { Multivariate } \\
\text { analysis } \\
\mathbf{p}\end{array}$ \\
\hline \multicolumn{5}{|l|}{$\begin{array}{l}\text { Age groups } \\
\text { (years) }\end{array}$} \\
\hline$\leq 2$ years & 6 & $\begin{array}{l}10.46(0.13- \\
13.16)\end{array}$ & & \\
\hline $2-12$ years & 41 & $\begin{array}{l}13.17(8.45- \\
17.30)\end{array}$ & 0.11 & $<0.001$ \\
\hline$>12$ years & 21 & $8.96(0.13-12.35)$ & 0.61 & 0.15 \\
\hline \multicolumn{5}{|l|}{ Gender } \\
\hline Male & 51 & $\begin{array}{l}10.63(3.51- \\
16.28)\end{array}$ & 0.24 & 0.31 \\
\hline Female & 17 & $\begin{array}{l}12.16(10.29- \\
17.03)\end{array}$ & & \\
\hline \multicolumn{5}{|l|}{ Ethnicity } \\
\hline African & 5 & $\begin{array}{l}17.30(13.16- \\
18.90)\end{array}$ & 0.02 & $<0.01$ \\
\hline Asiatic & 7 & $\begin{array}{l}14.26(7.44- \\
18.32)\end{array}$ & 0.03 & 0.05 \\
\hline $\begin{array}{l}\text { South Ameri- } \\
\text { can }\end{array}$ & 13 & $\begin{array}{l}12.16(10.87- \\
16.67)\end{array}$ & 0.04 & 0.05 \\
\hline Caucasian & 43 & $9.6(0.19-15.72)$ & & \\
\hline
\end{tabular}

Value reported in bold those statistically significant $(p<0.05)$

$I Q R$ interquartile range

observed $(\mathrm{p}<0,001)$. In fact, INH plasma concentration progressively increased with therapy duration. [24].

In the present study, no statistically significant differences were observed with regard to reason for investigation, patient and parent place of birth, or associated drugs and diagnosis. Regarding the correlation between low plasma concentration of INH and sex, a statistically significant difference was observed in our study. In fact, 
INH plasma concentration was found to be higher in older males $(\geq 12$ years) than females $(\mathrm{p}=0.004)$.

In this regard, in 2003, Ray et al. analyzed INH plasma concentrations in 85 adults treated with INH and observed significantly higher values in the INH plasma concentrations in males compared to females. They attributed the difference to the fact that females presented a higher dose when normalized for bodyweight [22]. This result can be considered in line with our finding, based on the fact that INH plasma concentration was found to be significantly higher in adolescent males compared to females. However, accurate comparisons between these results in adults and current findings in children are difficult, in light of the impact of dosages and the pharmacokinetic differences between these two categories. In contrast, Prahl et al. in 2014, investigated the clinical correlation with 2-h plasma concentrations of INH, RIF, PZN and ETB in 35 adults. No statistically significant difference was observed regarding drug formulation, dosage, therapy duration and gender but a correlation between low plasma levels and therapy failure was observed. In fact, five out 35 patients experienced disease relapse or died during treatment. Compared with enrolled patients with a successful treatment outcome, cases which experienced therapy failure presented lower INH plasma concentrations [26].

This finding was confirmed by a study involving 39 children with active TB aged 2-16 years conducted by Ranjalkar et al. in 2017. No significant effect of sex, age, body weight, type of TB, nutritional status and treatment regimen on plasma concentrations of either INH or RIF was observed [27].

Furthermore, Magis-Escurra et al., in a study on 41 adults, observed no statistically significant difference when considering sex, age and body mass index (BMI) on INH and RIF plasma concentrations [28].

A statistically significant difference was also observed between different age groups $(\leq 2$ years, 2-12 years, $>12$ years) regarding INH plasma concentration. In fact, INH levels were statistically significantly lower in younger children compared to the older age groups in both the univariate and multivariate analysis $(\mathrm{p}<0.001$ and $\mathrm{p}<0.001)$.

This finding was also highlighted in a study conducted by Schaaf et al. in 64 children. Authors reported a significant age-related decline in the elimination rate constant. In fact, younger children eliminated INH faster than older children, and children as a group faster than adults [17].

In 2009 McIlleron et al. evaluated plasma concentrations of antitubercular drugs in 56 southern African children. Peak plasma concentrations were below the recommended therapeutic ranges in almost $70 \%$ of patients. They reported that younger children required higher doses of INH per kilogram of body weight in order to reach INH plasma concentrations similar to those in adults [29]. These results can be attributed to the faster hepatic metabolism of younger children with an increased drug clearance normalized for body weight [30].

In addition to pharmacokinetic differences, lower drug plasma concentrations in younger children may be also related to the absence of pediatric formulations of antitubercular drugs, especially for INH. In this regard, Pouplinet al. investigated INH, PZN and RIF content uniformity in split tables used in the treatment of childhood TB. The authors reported that the content uniformity of antitubercular drugs in solid formulations is altered when the whole tablet is broken. [31].

A statistically significant lower plasma concentration of INH and RIF was also observed in older children $(>12$ years) compared to the age group of children aged $2-12$ years $(\mathrm{p}<0.001)$. This finding could be related to the lower oral medication adherence of adolescents, described in the literature both for TB treatment regimens and for prolonged treatments for chronic conditions [32-34]. Several strategies have been proposed based on medication adherence apps, wirelessly observed therapy, video directly observed therapy, short message service reminders and adolescent education and counselling services, with a positive impact on treatment adherence [35-39].

When patient place of birth is taken into account, a statistically significant higher plasma concentration was observed in Africans compared to other ethnicities in the multivariate analysis $(\mathrm{p}<0.001)$. The influence of race and genetic polymorphisms on drug concentration has been evaluated in the literature to support tailored treatments based on genetic diversity [40-42].

This study presents several limitations. Due to the real-life design of the study, conducted during scheduled clinical evaluations, we were not able to calculate area under the curve (AUC) and maximum or minimum plasma concentrations. No information regarding fasting conditions before drug intake was available. Moreover, no information regarding cure rates and TB treatment outcomes is available. A clinical follow-up is fundamental to determining whether low INH and RIF plasmatic levels are associated with treatment failures and relapses. Larger studies, especially in children under 2 years of age are needed to confirm these findings.

\section{Conclusions}

About $30 \%$ of children with plasma concentrations of INH or RIF under therapeutic levels were identified in the present study, with lower INH plasma concentrations 
in younger children. Low drug plasma concentrations can lead to poor therapy outcomes and to the onset of drug-resistant strains. Monitoring patients' drug plasma concentrations in order to fix dosages where necessary, especially in children under 2 years of age, can make treatment more patient-tailored. Further studies are necessary in order to apply TDM in children, to identify precise therapeutic reference ranges, based on different age groups and on genetic characteristics.

\begin{abstract}
Abbreviations
TB: Tuberculosis; WHO: World Health Organization; INH: Isoniazid; RIF: Rifampicin; TDM: Therapeutic drug monitoring; HIV: Human immunodeficiency virus; HLPC: High Performance Liquid Chromatography; SD: Standard deviation; IQR: Interquartile range; GEE: Generalized estimating equation model; PZN: Pyrazinamide; ETB: Ethambutol.
\end{abstract}

\section{Acknowledgements}

None.

\section{Authors' contributions}

$L G$ and $A N$ conceived the study and approved the final version of the manuscript. CT, GB, LB, CM, EC, EV and BB collected the data and wrote the manuscript. MIC, SF and AN were responsible for laboratory procedures and data revision. LT performed the statistical analysis. All authors have read and approved the manuscript.

\section{Funding}

None.

\section{Availability of data and materials}

The datasets used and/or analyzed during the current study are available from the corresponding author on reasonable request.

\section{Declarations}

\section{Ethics approval and consent to participate}

The study was approved by the ethical committee of Anna Meyer Children's University Hospital (20/12/2018-188/2018). Written informed consent was obtained from a parent or guardian for participants under 16 years old.

\section{Consent for publication}

Not applicable.

\section{Competing interests}

The authors declare that they have no competing interests in this section.

\section{Author details}

${ }^{1}$ Post Graduate School of Pediatrics, University of Florence, Florence, Italy. ${ }^{2}$ University of Florence, Florence, Italy. ${ }^{3}$ Department of Health Sciences, Clinical Pharmacology and Oncology Section, University of Florence, Florence, Italy. ${ }^{4}$ Infectious Diseases Unit, Meyer Children's University Hospital, Florence, Italy. ${ }^{5}$ Department of Health Sciences, University of Florence, Anna Meyer Children's University Hospital, Florence, Italy.

Received: 1 November 2020 Accepted: 17 May 2021

Published online: 21 October 2021

\section{References}

1. World Health Organization. Global TB report. 2019. https://www.who.int/ tb/publications/global_report/en/. Accessed Oct 2020.

2. Sheddon JA, Shingadia D. Epidemiology and disease burden of tuberculosis in children: a global perspective. Infect Drug Resist. 2014;7:153-65.
3. Ritz N, Curtis N. Novel concepts in the epidemiology, diagnosis and prevention of childhood tuberculosis. Swiss Med Wkly. 2014;144:14000.

4. Kimberlin DW, Brady MT, Jackson MA. Medical evaluation for infectious diseases for internationally adopted, refugee, and immigrant children. Red Book. Report of Committee on Infectious Diseases. Elk Grove Village 2012; 2:194-201.

5. Kumar AKH, Chandrasekaran V, Kannan JT, et al. Intrapatient variability in plasma rifampicin \& isoniazid in tuberculosis patients. Indian J Med Res. 2018;147:287-92.

6. Jong SP, Jae YL, Yeon LJ, et al. Serum levels of antituberculosis drugs and their effect on tuberculosis treatment outcome. Antimicrob Agents Chemother. 2016;60(1):92-8.

7. Baietto L, Calcagno A, Motta I, et al. A UPLC-MS-MS method for the simultaneous quantification of first line antituberculars in plasma and PBMCs. J Antimicrob Chemother. 2015;70:2572-5.

8. Morita IA, Saktiawati S, Harkema M, et al. Optimal sampling strategies for therapeutic drug monitoring of first-line tuberculosis drugs in patients with tuberculosis. Clin Pharmacokinet. 2019;1:1-10.

9. Motta I, Calcagno A, Bonora S. Pharmacokinetics and pharmacogenetics of antitubercular drugs: a tool for treatment optimization? Expert Opin Drug Metab Toxicol. 2018;14:59-82.

10. Prahl JB, Lundqvist M, Bahl JMC, et al. Simultaneous quantification of isoniazid, rifampicin, ethambutol and pyrazinamide by liquid chromatography/tandem mass spectrometry. APMIS. 2016;124:1004-15.

11. Zuur AM, Bolhuis MS, Anthony R, et al. Current status and opportunities for therapeutic drug monitoring in the treatment of tuberculosis. Expert Opin Drug Metab Toxicol. 2016;12(5):509-21.

12. Sturkenboom MG, Mulder LW, de Jager A, et al. Pharmacokinetic modeling and optimal sampling strategies for therapeutic drug monitoring of rifampin in patients with tuberculosis. Antimicrob Agents Chemother. 2015;59:4907-13.

13. Sotgiu G, Alffenaar JW, Centis R, et al. Therapeutic drug monitoring: how to improve drug dosage and patient safety in tuberculosis treatment. Int J Infect Dis. 2014;32:101-4.

14. World Health Organization. Rapid advice: treatment of tuberculosis in children. WHO/HTM/TB/2010.13. World Health Organization, Geneva; 2010.

15. World Health Organization. Guidance for national tuberculosis programs on the management of tuberculosis in children. Geneva: World Health Organization; 2006

16. Mcllleron $\mathrm{H}$, Willemse $\mathrm{M}$, Werely $\mathrm{CJ}$, et al. Isoniazid plasma concentrations in a cohort of South African children with tuberculosis: implications for international pediatric dosing guidelines. Clin Infect Dis. 2009;48:1547-53.

17. Schaaf HS, Parkin DP, Seifart HI, et al. Isoniazid pharmacokinetics in children treated for respiratory tuberculosis. Arch Dis Child. 2005;90:614-8.

18. Liu P, Fu Z, Jiang J, et al. Determination of isoniazid concentration in rabbit vertebrae by isotope tracing technique in conjunction with HPLC. Biomed Chromatogr. 2013;27:1150-6.

19. Liu J, Sun J, Zhang W, et al. HPLC determination of rifampicin and related compounds in pharmaceuticals using monolithic column. J Pharm Biomed Anal. 2008;46:405-9.

20. Goodman LS, Brunton LL, Chabner B, et al. Goodman \& Gilman's pharmacological basis of therapeutics. New York: McGraw-Hill; 2011.

21. American Academy of Pediatric, et al. Tuberculosis. In: Kimberlin DW, Brady MT, Kackson MA, Jakson MA, et al., editors. Red Book: 2018 report of the committee on infectious diseases. 31st ed. Elk Grove Village: American Academy of Pediatrics; 2018. p. 829-53.

22. Ray J, Gardiner Marriott D, et al. Managing antituberculosis drug therapy by therapeutic drug monitoring of rifampicin and isoniazid. Intern Med J. 2003;33:229-34.

23. Schaff HS, Parkin DP, Seifart H, et al. Isoniazid pharmacokinetics in children treated for respiratory tuberculosis. Arch Dis Child. 2005;90:614-8.

24. Fahimi F, Kobarfard F, Tabarsi P, et al. Isoniazid blood levels in patients with pulmonary tuberculosis at a tuberculosis referral center. Chemotherapy. 2011;57:7-11.

25. Moussa LA, Khassiuani CE, Soulayman R, et al. Therapeutic isoniazid monitoring using a simple high-performance liquid chromatographic method with ultraviolet detection. J Chromatogr B. 2001;766:181-7. 
26. Prahl JB, Johansen IS, Cohen AS, et al. Clinical significance of $2 \mathrm{~h}$ plasma concentrations of first line antituberculosis drugs: a prospective observational study. J Antimicrob Chemother. 2014;69:2841-7.

27. Ranjalkar J, Sumith KM, Verghese VP, et al. Isoniazid and rifampicin concentrations in children with tuberculosis with either a daily or intermittent regimen: implications for the revised RNTCP 2012 doses in India. Int J Antimicrob Agents. 2018;51:663-9.

28. Magis EC, Later NH, Alffenaar JWC, et al. Population pharmacokinetics and limited sampling strategy for fist line tuberculosis drugs and moxifloxacin. Int J Antimicrob Agents. 2014;44:229-34.

29. Mcllleron $\mathrm{H}$, Willemse M, Werely CJ, et al. Isoniazid plasma concentrations in a cohort of South African children with tuberculosis: implications for International Pédiatrie Dosing Guideline. Clin Infect Dis. 2009;48(11):1547-53.

30. Thee S, Seddon JA, Donald PR, et al. Pharmacokinetics of isoniazid, rifampin, and pyrazinamide in children younger than two years of age with tuberculosis: evidence for implementation of revised World Health Organization recommendations. Antimicrob Agents Chemother 2011;55:5560-7

31. Pouplin T, Phuong PN, Toi $P$, et al. Isoniazid, pyrazinamide and rifampicin content variation in split fixed-dose combination tablets. PLoS ONE. 2014;9:102047.

32. Alipanah N, Jarlsberg L, Miller C, et al. Adherence interventions and outcomes of tuberculosis treatment: a systematic review and meta-analysis of trials and observational studies. PLoS Med. 2018;15:e1002595.

33. Gebreweld FH, Kifle MM, Gebremicheal FE, et al. Factors influencing adherence to tuberculosis treatment in Asmara, Eritrea: a qualitative study. J Health Popul Nutr. 2018;37:1.

34. Faint NR, Staton JM, Stick SM, et al. Investigating self-efficacy, disease knowledge and adherence to treatment in adolescents with cystic fibrosis. J Paediatr Child Health. 2017:53:488-93.

35. Curtis K, Lebedev A, Aguirre E, et al. A medication adherence app for children with sickle cell disease: qualitative study. JMIR Mhealth Uhealth. 2019;7:e8130
36. Sumari-de Boer M, Pima FM, Ngowi KM, et al. Implementation and effectiveness of evriMED with short messages service (SMS) reminders and tailored feedback compared to standard care on adherence to treatment among tuberculosis patients in Kilimanjaro, Tanzania: proposal for a cluster randomized controlled trial. Trials. 2019;20:426.

37. Badawy SM, Kuhns LM. Texting and mobile phone app interventions for improving adherence to preventive behavior in adolescents: a systematic review. JMIR Mhealth Uhealth. 2017;5:e50.

38. Lim JK, Lee YJ, Park JH. Medication-related knowledge and medication adherence in pediatric and adolescent patients with inflammatory bowel disease. J Korean Med Sci. 2020;35:e92.

39. Kosse RC, Koster ES, Kaptein AA, et al. Asthma control and quality of life in adolescents: the role of illness perceptions, medication beliefs, and adherence. J Asthma. 2019:57:1145-54.

40. Naidoo A, Chirehwa M, Ramsuran V, et al. Effects of genetic variability on rifampicin and isoniazid pharmacokinetics in South African patients with recurrent tuberculosis. Pharmacogenomics. 2019;20:225-40.

41. Chigutsa E, Visser ME, Swart EC, et al. The SLCO1B1 rs4149032 polymorphism is highly prevalent in South Africans and is associated with reduced rifampin concentrations: dosing implications. Antimicrob Agents Chemother. 2011;55:4122-7.

42. Devaleenal Daniel B, Ramachandran G, Swaminathan S. The challenges of pharmacokinetic variability of first-line anti-TB drugs. Expert Rev Clin Pharmacol. 2017;10:47-58.

\section{Publisher's Note}

Springer Nature remains neutral with regard to jurisdictional claims in published maps and institutional affiliations.
Ready to submit your research? Choose BMC and benefit from:

- fast, convenient online submission

- thorough peer review by experienced researchers in your field

- rapid publication on acceptance

- support for research data, including large and complex data types

- gold Open Access which fosters wider collaboration and increased citations

- maximum visibility for your research: over $100 \mathrm{M}$ website views per year

At BMC, research is always in progress.

Learn more biomedcentral.com/submissions 